Research Article

\title{
Investigation of Flexural Capacity of Concrete Containing Liquid Silicone Rubber
}

\author{
Alireza Khaloo $\mathbb{D i D}^{1}$ and Yaser Parvin Darabad $\mathbb{D i D}^{2}$ \\ ${ }^{1}$ Civil Engineering Department, Sharif University of Technology, Center of Excellence in Structures and Earthquake Engineering, \\ Tehran, Iran \\ ${ }^{2}$ Sharif University of Technology International Campus, Kish Island, Iran
}

Correspondence should be addressed to Alireza Khaloo; khaloo@sharif.edu

Received 24 November 2020; Revised 8 February 2021; Accepted 11 February 2021; Published 23 February 2021

Academic Editor: Seyed Mahdi Seyed Kolbadi

Copyright (c) 2021 Alireza Khaloo and Yaser Parvin Darabad. This is an open access article distributed under the Creative Commons Attribution License, which permits unrestricted use, distribution, and reproduction in any medium, provided the original work is properly cited.

\begin{abstract}
Despite the great use of concrete, tensile strength and low flexibility and brittleness are its weaknesses. Many solutions have been provided to eliminate the mentioned defects. In order to increase the flexibility of concrete in previous studies, crushed rubber tire particles have been added to concrete. Recycling car tires helps the environment and makes concrete much more flexible than regular concrete. In this research, silicone rubber has been replaced by $0 \%, 2 \%, 4 \%, 8 \%, 12.5 \%, 25 \%$, and $50 \%$ of mineral aggregates. This rubber was initially in liquid form, which, after mixing with ordinary concrete, dispersed into the concrete texture and formed a uniform mixture, and this liquid rubber became a flexible solid after 24 hours. Concrete containing silicone rubber is a new composite with new properties, and in this research, it is called Hybrid Silicone Rubber Concrete (HSRC). Also, to evaluate the effect of aggregate size in making experimental specimens, two coarse to fine aggregate ratios of $G / S=0.7,1.1$ were considered. Flexural strength tests were performed on hardened concrete beam specimens. The results showed that, with increasing the amount of silicone rubber in concrete, flexural strength decreased and this percentage of strength reduction was compared with the percentage of reduction in compression and splitting tensile strength. It was found that the reduction of flexural strength was less than compression and splitting tensile strength. Larger deformation was observed during all tests when the concentration of silicone rubber increased. It was observed that the higher the amount of silicone rubber in the specimens, the less noise and the less separation of aggregates with which the failure of the specimens was associated.
\end{abstract}

\section{Introduction}

Concrete is one of the most widely used materials in construction, but it is weak against tensile forces. Cement-based composite materials are cracked when subjected to tensile load, and the deformation corresponding to the cracking load is also very small relative to the ductile material. By increasing the corresponding displacement of cracking loads, the energy absorption capacity of the materials increases. To increase the ductility of concrete, fiber reinforced concrete has been developed since the 1960s [1]. Various types of fibers, such as steel, carbon, and glass fiber, were used to increase bending strength and concrete performance. Another way to increase the ductility of concrete is to add rubber particles to concrete. In previous studies, waste tire rubber particles have been replaced with mineral aggregates [2]. The use of waste tire rubber has two benefits: one of them is the reduction of waste tire problem, and the other is the less consumption of natural resources for concrete production. In the first report on the use of waste tire rubber particles in concrete, chips and crumb rubber was used as a substitute for mineral aggregates in plain concrete. The results of the compressive tests showed that increasing the number of rubber particles in the concrete reduces the compressive strength of the concrete, but the flexibility is significantly increased. In a previous research, mechanical properties of concrete containing a high volume of the waste tire-rubber particles were investigated [3]. Recycling is considered as one of the measures of sustainable methods. The physical features of the asphalt mixture under the 
influence of accelerated aging for asphalt concrete were determined [4]. Dynamic Parameter and Experimental Study of Tuned Slab Damper was conducted by Xu et al. Experimental result showed that the vibration of the absorbing plate was wasted by the damping property of the elastic element in order to reduce the peak value of the track vibration [5]. The study revealed that the addition of rubber particles to concrete has improved the brittle nature of the concrete and its low toughness, but the ultimate strength has significantly decreased. Flexural and compression tests were performed on concrete specimens including two types of rubber particles, such as fine crumb rubber and tire chips [6]. The waste tire in the form of fiber with various aspects of ratio was used in concrete. Increase in ductility and loss in compressive strength have been reported [7]. Recycled tire rubber particles replaced mineral aggregates in concrete and results showed that they reduced mechanical properties (compressive, flexural, and splitting tensile strength) but increased the impact resistance to $400 \%$ when $20 \%$ coarse aggregates and $20 \%$ fine aggregates are replaced by tire rubber particle, respectively [8]. Also, high volume recycled car tires were added to the concrete along with silica and the impact energy of the concrete was investigated. According to the results, energy absorption and impact energy capacity increased but compressive and tensile strengths decreased [9]. An experimental study on the use of latex in cement composites showed that tensile strength increased [10]. Replacement of mineral coarse aggregate with the tire rubber particles caused the reduction in compressive and flexural strength. As reported, the decrease in flexural strength was twice that in compressive strength [11]. According to the reported results, increasing the amount of rubber in rubberized concrete increases energy absorption and ductility [3]. The use of rubber particles in concrete affects the porosity and permeability of concrete. The permeability in porous materials has been studied [12]. In a study on the effect of the use of the silica fume in rubberized concrete (RC), it was concluded that silica fume improved mechanical properties of RC and reduced the amount of the reduction in compressive strength [13]. In most studies on RC, the impact of rubber concentration on concrete was studied. Generally, in these studies, a normal concrete mix has been selected, and different $\mathrm{RC}$ mixes are provided by introducing a different amount of tire rubber replaced with mineral aggregates in the original mix and then mechanical properties of the RCs are compared to the original concrete. Rubberized concrete exhibited lower compressive strength [6] and unit weight, compared to original normal concrete. RCs usually exhibit lower elastic modulus [11], tensile strength [12], and workability [13, 14], higher ductility [3], and higher energy absorption capacity [15]. The use of liquid silicone rubber coatings as novel and successful alternative design has been introduced by applying the coating operation on the surface of the isolator of the distribution transformers [14]. Effect of Styrene-Butadiene Rubber (SBR), silica fume, and fly ash on compressive and flexure strengths of mortars was investigated by $\mathrm{Hu}$ Feng et al., and the result revealed that SBR reduced the mechanical strength of the mortars. SEM and EDS studies showed that SBR prevented the formation of albite, whereas silica content from silica fumes and fly ash changed $\mathrm{CaCO}_{3}$ to Wollastonite (a white loose powder), which reduced the mechanical strength of mortars [16]. The purpose of this research is to investigate the flexural and compressive behavior of concrete containing room temperature vulcanization (RTV) liquid silicone rubber. For this purpose, the mineral has been replaced by aggregates liquid silicone rubber in various volumetric percentages. Experimental observations and explanations related to the behavior of HSRC under flexural and compressive tests are presented. Some weaknesses of concrete are low tensile strength and flexural strength against compressive strength. Concrete is also classified as a brittle material with low flexibility and energy absorption [17]. The use of silicone rubber in concrete increases the ductility of concrete and its energy absorption capacity, and increasing ductility improves the brittle nature of concrete and reduces the process of cracking and crack growth in concrete. Increasing the energy absorption capacity of concrete improves the seismic performance of structures and increasing the ductility also increases the deformation of flexural members and delays the occurrence of cracks [18].

\section{Experimental Program}

\subsection{Materials and Methods}

2.1.1. Liquid Silicone Rubber RTV. Liquid silicone rubber is a rubber-like material that is widely used in the industry [15]. Liquid silicone rubber RTV is generally stable, nonreactive, and compatible with the environment. For these properties and ease of working and shaping, silicone rubber can be found in a wide variety of products including electrical industry, instrument, medical device, wearing, and in many other fields of the industry [19]. Liquid silicone rubber RTV used in this study consists of two parts. One is a liquid silicone rubber polymer, and another is a hardener. 24 hours after mixing two components, liquid silicone rubber becomes solid flexible rubber. The characteristic of the silicone rubber is presented in Table 1.

2.1.2. Mixed Material. Portland cement in accordance with ASTM C150 standard with a specific gravity of $3.17 \mathrm{~g} / \mathrm{cm}^{3}$ was used to make the specimens. Mineral aggregates including gravel with the maximum size of $19 \mathrm{~mm}$ and sand with the maximum size of $4.75 \mathrm{~mm}$ have been used as coarse and fine aggregates, respectively. The mineral aggregates from broken rock stone have been used. Grading curvature and the properties of aggregates are presented in Figure 1 and Table 2, respectively. To enhance the workability of the mixture, a polycarboxylate-based superplasticizer was used.

2.2. Concrete Mixtures. In order to study the HSRC mechanical properties, seven series of concrete mixtures were used. Liquid silicone rubber concentration was taken as the main variable in the experiment, which substituted the 0,2 , $4,8,12.5,25$, and 50 percent to the total mineral aggregate 
TABLE 1: Silicone rubber specifications.

\begin{tabular}{lccc}
\hline Property & Min value & Max value & SI unit \\
\hline Density & 1.1 & 2.3 & $\mathrm{Mg} / \mathrm{m}^{3}$ \\
Bulk modulus & 1.5 & 2 & $\mathrm{GPa}$ \\
Compressive strength & 10 & 30 & $\mathrm{MPa}$ \\
Elastic limit & 2.4 & 5.5 & $\mathrm{MPa}$ \\
Endurance limit & 2.28 & 5.23 & $\mathrm{MPa}$ \\
Fracture toughness & 0.03 & 0.7 & $\mathrm{MPa} \cdot \mathrm{m}^{1 / 2}$ \\
Modulus of rupture & 2.4 & 5.5 & $\mathrm{MPa}$ \\
Poisson's ratio & 0.47 & 0.49 & \\
Shear modulus & 0.0003 & 0.02 & $\mathrm{GPa}$ \\
Tensile strength & 2.4 & 5.5 & $\mathrm{MPa}$ \\
Young's modulus & 0.001 & 0.05 & $\mathrm{GPa}$ \\
\hline
\end{tabular}

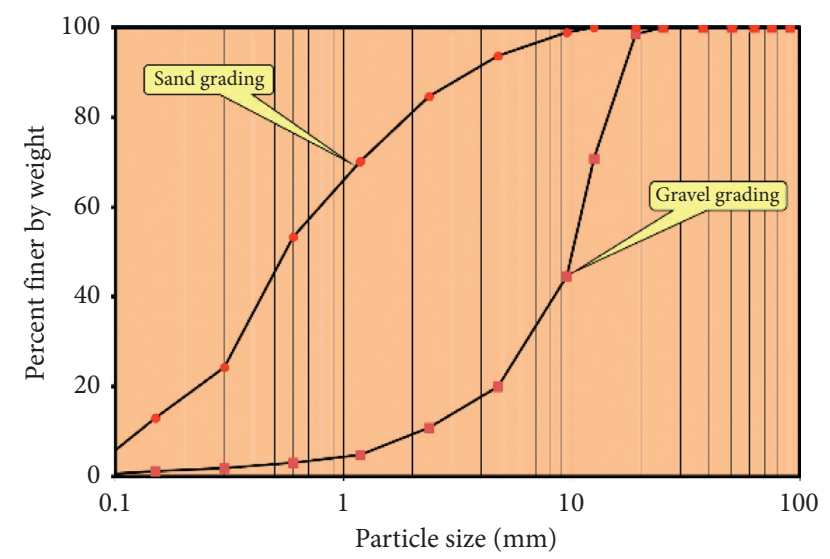

Figure 1: Grading of mineral aggregates.

volume. In order to investigate the effect of the coarse aggregate to fine aggregate ratio $(G / S)$ on concrete behavior, two ratios of 1.1 and 0.7 were considered. Water to cement ratio was 0.4 for all specimens. Water absorption of aggregates was considered for making the specimens. The amount of superplasticizer used in the mixture was $2 \%$ of the cement weight. Labeling of the specimens was performed using two factors, $G / S$ and silicone rubber concentration. To identify the $G / S$, HF (high mineral fine aggregate with $G /$ $S=0.7$ ) and LF (low mineral fine aggregate with $G / S=1.1$ ) were used. For example, LF-G2S2 mixture indicates liquid silicone rubber replaced by $2 \%$ of fine and coarse aggregate volume using low sand content $(G / S=1.1)$. The proportions of the concrete mixture and experimental program are given in Tables 3 and 4, respectively.

2.3. Manufacturing of Specimens and Testing. To make hybrid concrete specimens, at first, the cement is mixed with sand and gravel and then water containing superplasticizer is added to the mixture gradually. Liquid silicone rubber is prepared in such a way that liquid rubber is combined with its hardener. This mixture turns from liquid rubber to flexible solid rubber after 24 hours. The liquid silicone rubber mixture is added to the ordinary concrete, and the mixture is stirred to distribute the liquid silicone rubber uniformly throughout the concrete. For each mix design, cylindrical specimens $150 \times 300 \mathrm{~mm}$ (diameter $x$ height) and beams $100 \times 100 \times 350 \mathrm{~mm}$ were prepared. All specimens were manufactured according to ASTM C 192/C-06 [20]. Specimens were remolded 24 hours after fabrication and then cured in a water tank at $25^{\circ} \mathrm{C}$ and 1 day before testing specimens were taken out of the water tank.

2.3.1. Test Method. For each mix design, slump and unit weight were measured in accordance to ASTM C143 [21] and ASTM C138 [22], respectively. Compression tests for hardened cylindrical specimens were performed according to standard ASTM C39, and splitting tensile tests were performed according to standard ASTM C496. To evaluate flexural strength, specimens were tested according to ASTM C78 [23]. The beam specimens installed as a hinge supported condition with $300 \mathrm{~mm}$ length between the two supports. Four-point flexural testing was conducted by a universal testing machine with $0.05 \mathrm{~mm} / \mathrm{sec}$ rate of loading and test setup is shown in Figure 2. All tests were performed on specimens at 28 days of age.

\section{Experimental Results and Discussion}

3.1. Workability and Unit Weight. According to the results depicted in Figure 3, increasing the amount of liquid silicone rubber in concrete reduced the slump and weight in the mixture. In this study, by replacing the amount of liquid silicon rubber with $50 \%$ by volume of aggregates, the reported slump value is equal to 4 . The reported greeting is appropriate in terms of executive work. The slump reported in this study is up to a maximum of $50 \%$ rubber, suitable for executive work. According to the results presented in Figure 3(b), with increasing the amount of silicone rubber in the mixture, the total weight decreases, which is due to the fact that the density of rubber is less than mineral aggregates.

3.2. Strength of Hardened Concrete. The experimental results of compressive, flexural, and splitting tensile strengths at the age of 28 days are presented in Table 5. The results demonstrate that, with increasing the amount of silicone rubber content in the mixture, all strengths such as flexural, compressive, and splitting tensile strength have decreased for both HF and LF specimens. This has been predictable based on previous studies on concretes in which crumb tire rubber has been added [3]. Figure 4 shows the percentage reduction in strength based on the percentage of silicone rubber in concrete. As shown in Figures 4(a) and 4(b), it is clear that as the amount of silicon rubber in the mixture increased, the compressive strength decreased more than the flexural and splitting tensile strength in the same silicone rubber content. Another point that can be drawn by referring to Figures 4(a) and 4(b) is that, as the amount of silicon rubber in the mixture increased, the flexural strength has decreased less than the compressive and tensile strength, which indicates that the sensitivity of the flexural strength to the increase of silicone rubber content in the mixture is less, compared to the compressive and tensile splitting strength. Also, the slope of the diagram in Figures 4(a) and 4(b) shows that when the amount of silicone rubber exceeded $12.5 \%$, the 
TABle 2: Properties of mineral aggregates.

\begin{tabular}{lcccc}
\hline Aggregate type & Specific gravity & Water absorption $(\%)$ & Fineness modulus & Unit weight $\left(\mathrm{kg} / \mathrm{m}^{3}\right)$ \\
\hline Coarse aggregate & 2.63 & 2.69 & NA & 1709.6 \\
Fine aggregate & 2.69 & 5.16 & 4.38 & 1729 \\
\hline
\end{tabular}

TABle 3: Experimental program.

\begin{tabular}{lccccc}
\hline $\begin{array}{l}\text { Specimen } \\
\text { designation }\end{array}$ & $\begin{array}{c}\text { Liquid silicone rubber content } \\
(\%)\end{array}$ by total aggregates & $\begin{array}{c}\text { Fine } \\
\text { aggregate (\%) }\end{array}$ & $\begin{array}{c}\text { Coarse } \\
\text { aggregate (\%) }\end{array}$ & $\begin{array}{c}\text { Superplasticizer to } \\
\text { cement ratio (\%) }\end{array}$ & $\begin{array}{c}\text { Replicates of compressive } \\
\text { test (at 28 days) }\end{array}$ \\
\hline LF-G0S0 & 0 & 100 & 100 & 2 & 3 \\
LF-G1S1 & 1 & 99 & 99 & 2 & 3 \\
LF-G2S2 & 2 & 98 & 98 & 2 & 3 \\
LF-G4S4 & 4 & 96 & 96 & 2 & 3 \\
LF-G12.5S12.5 & 12.5 & 87.5 & 87.5 & 75 & 3 \\
LF-G25S25 & 25 & 75 & 50 & 2 & 3 \\
LF-G50S50 & 50 & 50 & 100 & 2 & 3 \\
HF-G0S0 & 0 & 100 & 99 & 2 & 3 \\
HF-G1S1 & 1 & 99 & 98 & 2 & 3 \\
HF-G2S2 & 2 & 98 & 96 & 2 & 3 \\
HF-G4S4 & 4 & 96 & 87.5 & 2 & 3 \\
HF-G12.5S12.5 & 12.5 & 87.5 & 75 & 2 & 3 \\
HF-G25S25 & 25 & 75 & 50 & 2 & 3 \\
HF-G50S50 & 50 & 50 & & & 3 \\
\hline
\end{tabular}

TABle 4: Concrete mixture proportions.

\begin{tabular}{|c|c|c|c|c|c|c|c|c|}
\hline Specimen & $\begin{array}{c}\text { Water } \\
\text { (Lit) }\end{array}$ & $\begin{array}{l}\text { Cement } \\
\left(\mathrm{kg} / \mathrm{m}^{3}\right)\end{array}$ & $\begin{array}{l}\text { Gravel- } \\
\text { sand } G / S\end{array}$ & $\begin{array}{l}\text { Liquid silicone } \\
\text { rubber }\left(\mathrm{kg} / \mathrm{m}^{3}\right)\end{array}$ & $\begin{array}{c}\text { Coarse } \\
\text { aggregate }(\mathrm{kg} / \\
\left.\mathrm{m}^{3}\right)\end{array}$ & $\begin{array}{c}\text { Fine aggregate } \\
\left(\mathrm{kg} / \mathrm{m}^{3}\right)\end{array}$ & $\begin{array}{c}\text { Moisture of } \\
\text { gravel (\%) }\end{array}$ & Moisture of sand (\%) \\
\hline LF-G0S0 & 224 & 350 & \multirow{7}{*}{1.1} & 0.00 & 942.86 & 857.14 & 3 & 4 \\
\hline LF-G1S1 & 231 & 350 & & 12.67 & 933.43 & 848.57 & 3 & 3.2 \\
\hline LF-G2S2 & 240 & 350 & & 25.34 & 924.00 & 840.00 & 2 & 3 \\
\hline LF-G4S4 & 204 & 350 & & 50.69 & 905.14 & 822.86 & 4 & 5 \\
\hline $\begin{array}{l}\text { LF- } \\
\text { G12.5S12.5 }\end{array}$ & 216 & 350 & & 158.40 & 825.00 & 750.00 & 3 & 4 \\
\hline LF-G25S25 & 187 & 350 & & 316.79 & 707.14 & 642.86 & 5 & 5 \\
\hline LF-G50S50 & 184 & 350 & & 633.59 & 471.43 & 428.57 & 4 & 4.5 \\
\hline HF-G0S0 & 218 & 350 & \multirow{7}{*}{0.7} & 0.00 & 741.16 & 1058.80 & 4 & 4 \\
\hline HF-G1S1 & 238 & 350 & & 12.66 & 733.75 & 1048.21 & 4 & 1.3 \\
\hline HF-G2S2 & 240 & 350 & & 25.31 & 726.34 & 1037.62 & 3.2 & 2 \\
\hline HF-G4S4 & 236 & 350 & & 50.62 & 711.51 & 1016.45 & 3.2 & 2.3 \\
\hline $\begin{array}{l}\text { HF- } \\
\text { G12.5S12.5 }\end{array}$ & 226 & 350 & & 158.19 & 648.52 & 926.45 & 3 & 3.1 \\
\hline HF-G25S25 & 224 & 350 & & 316.39 & 555.87 & 794.10 & 2.1 & 3 \\
\hline HF-G50S50 & 204 & 350 & & 632.77 & 370.58 & 529.40 & 2 & 2.5 \\
\hline
\end{tabular}

slope of the strength reduction decreased. Detailed examination of Figures 4(a) and 4(b) shows that, by increasing the silicone rubber content by up to $25 \%$, it maintained a linear relationship between the increase in silicone rubber and the compressive strength and about $50 \%$ of the compressive strength was lost in $25 \%$ of the silicone rubber content. In the case where the amount of silicone rubber is more than $25 \%$, the amount of strength reduction slope decreases. This trend is clear for the amount of silicone rubber between 25 and 50, and in the amount of 50\% silicone rubber, the reduction of compressive strength is equal to $82.5 \%$, and this amount of reduction in compressive strength limits the structural use of HSRC. Figure 5 shows the effect of silicone rubber content on compressive strength, splitting tensile, and flexural strength on both LF and HF specimens. It can be seen that, in both HF and LF specimens, the slope of the bending strength reduction line is less than the tensile strength reduction and the slope of the tensile strength reduction line is less than the slope of the compressive strength reduction. In addition, the ratio of flexural strength to compressive strength $(f b / f c)$ and splitting tensile strength to compressive strength $(f t / f c)$ and the ration of flexural strength to splitting tensile strength, based on the experimental data, are presented in Table 6 . The results in Table 6 indicate that as long as the percentage of silicone rubber was between 0 and $12.5 \%$, the ratio of $(f t / f c)$ was about 0.1 , but with increasing the amount of silicone 


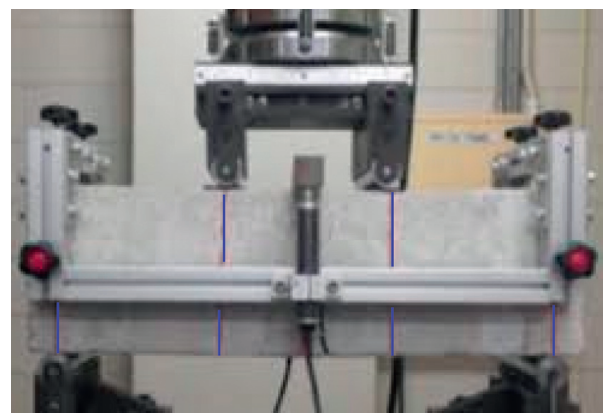

Figure 2: Test setup.

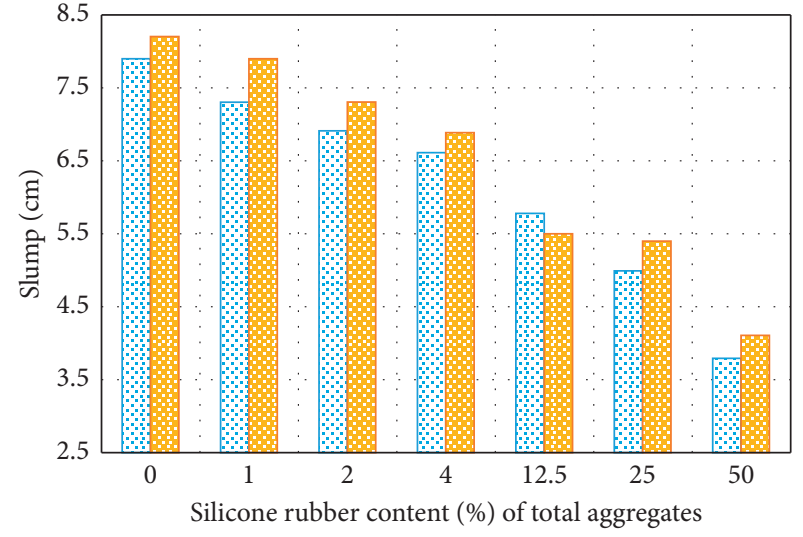

圆 $G / S=1.1$

圆 $G / S=0.7$

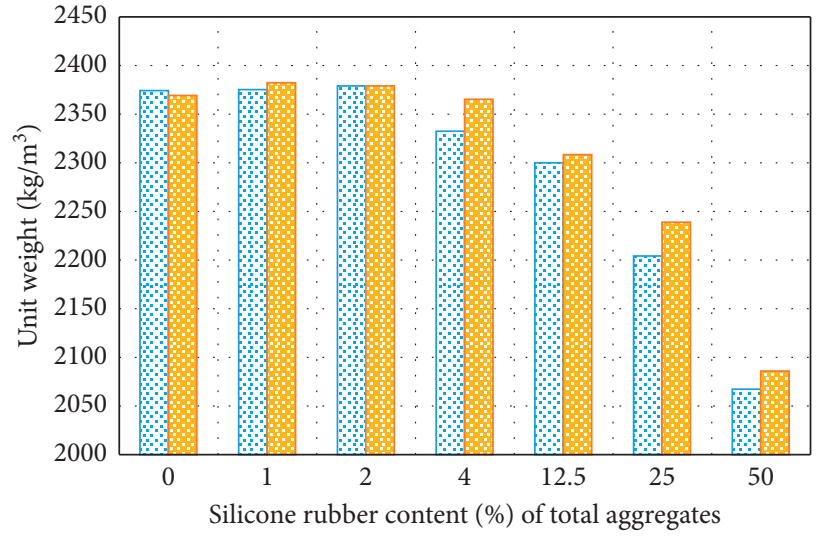

웅 $G / S=1.1$

圆 $G / S=0.7$

(a)

(b)

Figure 3: Properties of fresh HSRC. (a) Slump. (b) Unit weight of fresh HSRC.

TABLE 5: Changes in strengths with respect to control strength (LF specimens and HF specimens) and percentage of retained strength with respect to control specimen.

\begin{tabular}{|c|c|c|c|c|c|c|c|}
\hline $\begin{array}{l}\text { Concrete } \\
\text { mixture }\end{array}$ & $\begin{array}{c}\text { Total } \\
\text { rubber } \\
\text { content } \\
(\%)\end{array}$ & $\begin{array}{l}\text { Splitting } \\
\text { tensile } \\
\text { strength } f t \\
(\mathrm{MPa})\end{array}$ & $\begin{array}{l}f t \text { maintained } \\
\text { strength with } \\
\text { respect to the } \\
\text { control }(\%)\end{array}$ & $\begin{array}{l}\text { Bending } \\
\text { strength } f b \\
\quad(\mathrm{MPa})\end{array}$ & $\begin{array}{l}f b \text { maintained } \\
\text { strength with } \\
\text { respect to the } \\
\text { control }(\%)\end{array}$ & $\begin{array}{l}\text { Compressive } \\
\text { strength } f_{c} \\
(\mathrm{MPa})\end{array}$ & $\begin{array}{c}f \mathcal{c} \\
\text { maintained strength } \\
\text { with respect to the } \\
\text { control (\%) }\end{array}$ \\
\hline LF-G0S0 & 0 & $2 / 90$ & 100 & $4 / 06$ & $0 / 00$ & $29 / 33$ & 100 \\
\hline LF-G1S1 & 1 & $2 / 79$ & $96 / 41$ & $3 / 94$ & $2 / 78$ & $28 / 15$ & $95 / 98$ \\
\hline LF-G2S2 & 2 & $2 / 59$ & $89 / 24$ & $3 / 83$ & $5 / 59$ & $26 / 96$ & $91 / 93$ \\
\hline LF-G4S4 & 4 & $2 / 52$ & $87 / 04$ & $3 / 63$ & $10 / 61$ & $24 / 83$ & $84 / 66$ \\
\hline $\begin{array}{l}\text { LF- } \\
\text { G12.5S12.5 }\end{array}$ & $12 / 5$ & $1 / 84$ & $63 / 48$ & $2 / 93$ & $27 / 69$ & $17 / 59$ & $59 / 98$ \\
\hline LF-G25S25 & 25 & $1 / 39$ & $48 / 01$ & $2 / 27$ & $43 / 93$ & $10 / 71$ & $36 / 51$ \\
\hline LF-G50S50 & 50 & $0 / 84$ & $29 / 00$ & $1 / 74$ & $56 / 99$ & $5 / 17$ & $17 / 63$ \\
\hline HF-G0S0 & 0 & $3 / 64$ & 100 & $4 / 31$ & $0 / 00$ & $31 / 93$ & $100 / 00$ \\
\hline HF-G1S1 & 1 & $3 / 40$ & $93 / 48$ & $4 / 18$ & $3 / 03$ & $30 / 56$ & $93 / 48$ \\
\hline HF-G2S2 & 2 & $3 / 13$ & $85 / 95$ & $4 / 07$ & $5 / 47$ & $29 / 47$ & $85 / 95$ \\
\hline HF-G4S4 & 4 & $2 / 98$ & $81 / 93$ & $3 / 85$ & $10 / 52$ & $27 / 19$ & $81 / 93$ \\
\hline $\begin{array}{l}\text { HF- } \\
\text { G12.5S12.5 }\end{array}$ & $12 / 5$ & $2 / 29$ & $62 / 90$ & $3 / 08$ & $28 / 56$ & $19 / 08$ & $62 / 90$ \\
\hline HF-G25S25 & 25 & $1 / 78$ & $48 / 85$ & $2 / 37$ & $45 / 04$ & $11 / 66$ & $48 / 85$ \\
\hline HF-G50S50 & 50 & $1 / 09$ & $29 / 86$ & $1 / 78$ & $58 / 59$ & $5 / 57$ & $29 / 86$ \\
\hline
\end{tabular}




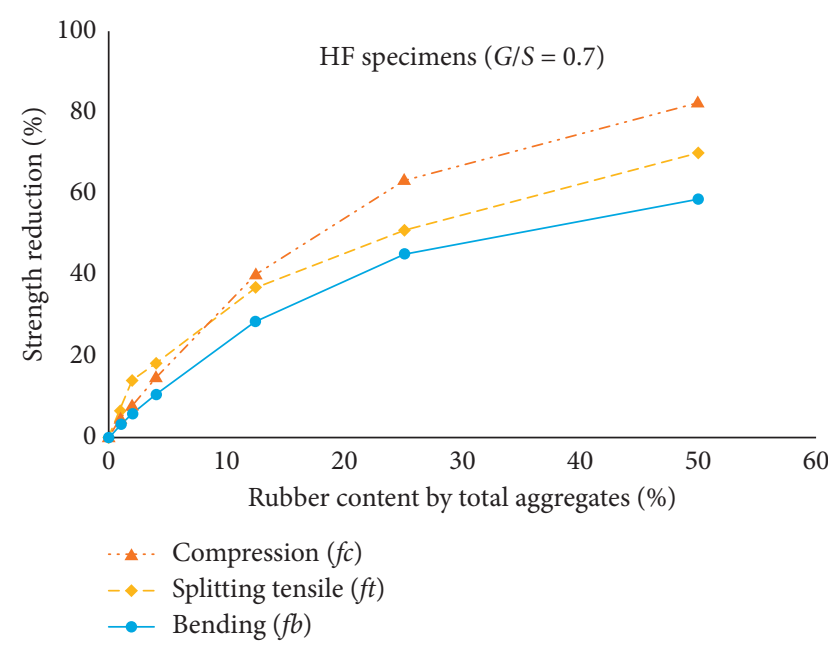

(a)

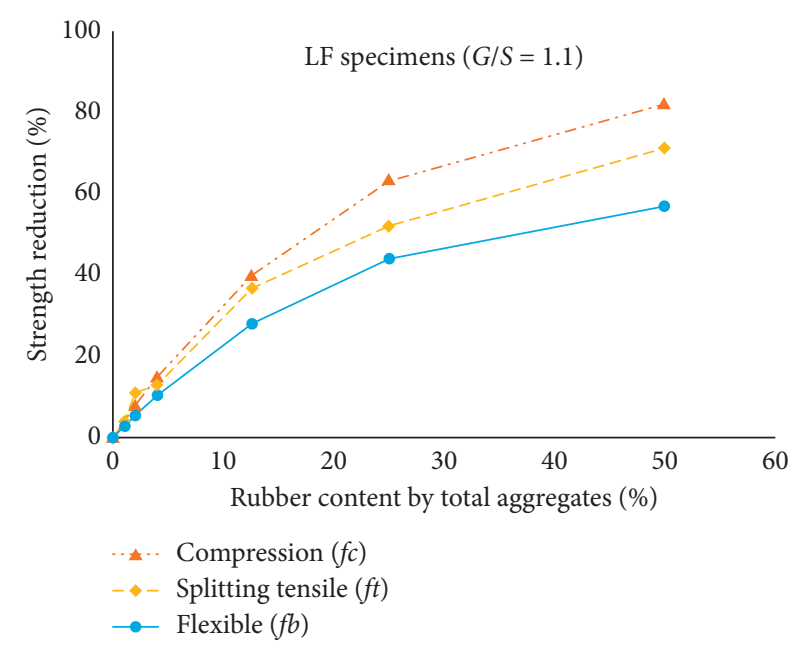

(b)

Figure 4: Comparison between strength reduction and silicone rubber content. (a) HF specimens. (b) LF specimens.

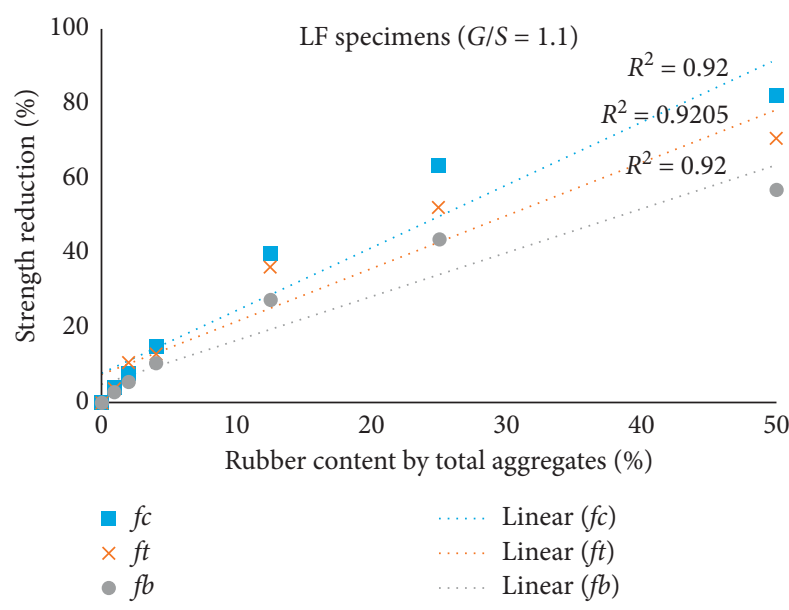

(a)

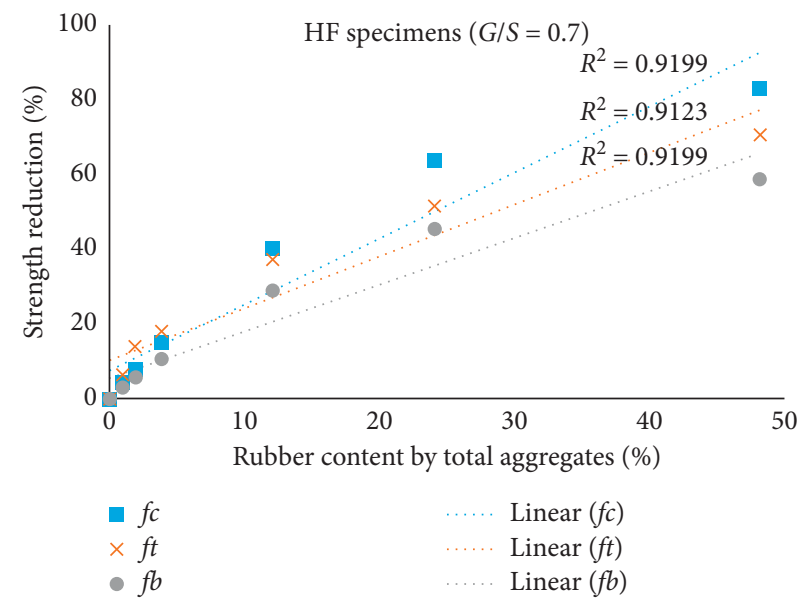

(b)

FIGURE 5: Effect of silicone rubber content on the compressive, tensile splitting, and bending strengths. (a) LF specimens. (b) HF specimens.

rubber from $12.5 \%$ to $50 \%$, the ratio of $(f t / f c)$ varies from 0.1 to $0.16 \%$ in the LF specimens, and also in the HF specimens when silicone rubber was between 0 and $12.5 \%$, the ratio of $(f t / f c)$ is about 0.11 and when increasing the amount of silicone rubber from $12.5 \%$ to $50 \%$, the ratio of $(f t / f c)$ varies from 0.11 to 0.195 . In examining the changes in the $(f b / f c)$ ratio according to the results of Table 6 , it can be obtained that as long as the percentage of silicone rubber was between 0 and $4 \%$, the ratio of $(f b / f c)$ was about 0.14 , but with increasing the amount of silicone rubber from $12.5 \%$ to $50 \%$, the ratio of $(f b / f c)$ varies from 0.17 to $0.34 \%$ in the LF specimens, and also in the HF specimens when silicone rubber was between 0 and $4 \%$, the ratio of $(f b / f c)$ is about 0.14 and when increasing the amount of silicone rubber from $12.5 \%$ to $50 \%$, the ratio of $(f b / f c)$ varies from 0.16 to 0.32 , and in a similar review for ratios $(f t / f b)$ as long as the percentage of silicone rubber was between 0 and $4 \%$, the ratio of $(f t / f b)$ was about 0.7 , but with increasing the amount of silicone rubber from $12.5 \%$ to $50 \%$, the ratio of $(f t / f b)$ varies from $0 /$
63 to $0.43 \%$ in the LF specimens, and also in the HF specimens when silicone rubber was between 0 and $4 \%$, the ratio of $(f t / f b)$ is about 0.71 and when increasing the amount of silicone rubber from $12.5 \%$ to $50 \%$, the ratio of $(f t / f b)$ varies from 0.74 to 0.61 . The effects of the various percentages of silicone rubber content on the retained compressive, splitting tensile, and bending strength compared to the control strength have been reported in Table 5 and depicted in Figure 6. The percentage changes in the retained strength to the amount of silicone rubber are given in Table 6. As shown in Table 6, when the amount of silicone rubber increased to $50 \%$, the percentage of compressive strength maintained was $17.63 \%$ of the LF control specimen and $29.8 \%$ of the HF control specimen and also the percentage of splitting tensile strength maintained for both LF and HF control specimen was $29 \%$. The percentage of flexural strength maintained for the LF control specimen was $57 \%$, and for HF control specimen, it was $58.5 \%$. It is significant that the rate of strength reduction with increasing 
TABLE 6: Comparison of strength ratios based on the silicone rubber content.

\begin{tabular}{|c|c|c|c|c|}
\hline Concrete mixture & Total rubber content $(\%)$ & $f t / f_{\mathcal{c}}(\mathrm{Exp})$. & $f b / f c$ (Exp.) & $f t / f b$ (Exp.) \\
\hline LF-G0S0 & 0 & $0 / 099$ & $0 / 138$ & $0 / 714$ \\
\hline LF-G1S1 & 1 & $0 / 100$ & $0 / 140$ & $0 / 710$ \\
\hline LF-G2S2 & 2 & $0 / 096$ & $0 / 142$ & $0 / 676$ \\
\hline LF-G4S4 & 4 & $0 / 101$ & $0 / 146$ & $0 / 695$ \\
\hline LF-G12.5S12.5 & 13 & $0 / 105$ & $0 / 167$ & $0 / 630$ \\
\hline LF-G25S25 & 25 & $0 / 130$ & $0 / 212$ & $0 / 611$ \\
\hline LF-G50S50 & 50 & $0 / 163$ & $0 / 338$ & $0 / 483$ \\
\hline HF-G0S0 & 0 & $0 / 114$ & $0 / 135$ & $0 / 844$ \\
\hline HF-G1S1 & 1 & $0 / 111$ & $0 / 136$ & $0 / 814$ \\
\hline HF-G2S2 & 2 & $0 / 106$ & $0 / 138$ & $0 / 768$ \\
\hline HF-G4S4 & 4 & $0 / 110$ & $0 / 142$ & $0 / 774$ \\
\hline HF-G12.5S12.5 & 13 & $0 / 120$ & $0 / 161$ & $0 / 744$ \\
\hline HF-G25S25 & 25 & $0 / 153$ & $0 / 203$ & $0 / 753$ \\
\hline HF-G50S50 & 50 & $0 / 194$ & $0 / 319$ & $0 / 609$ \\
\hline
\end{tabular}

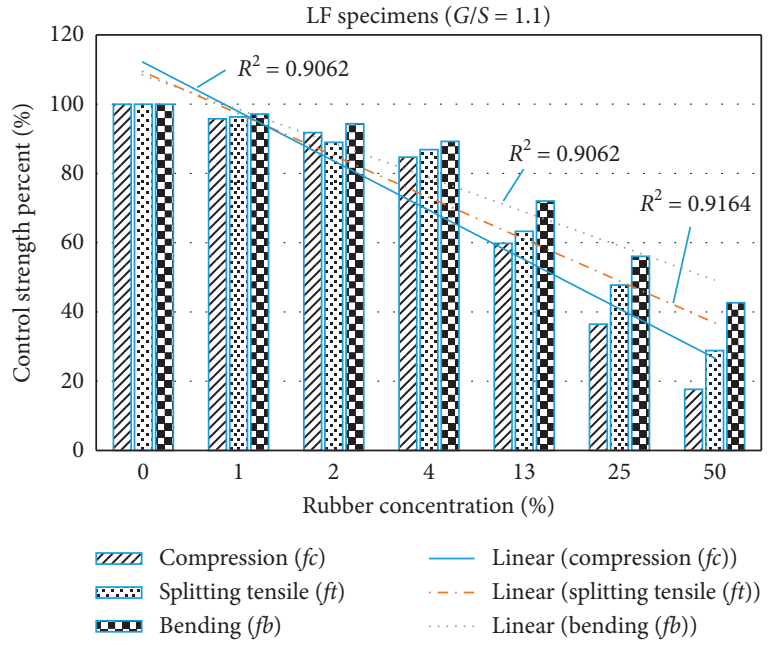

(a)

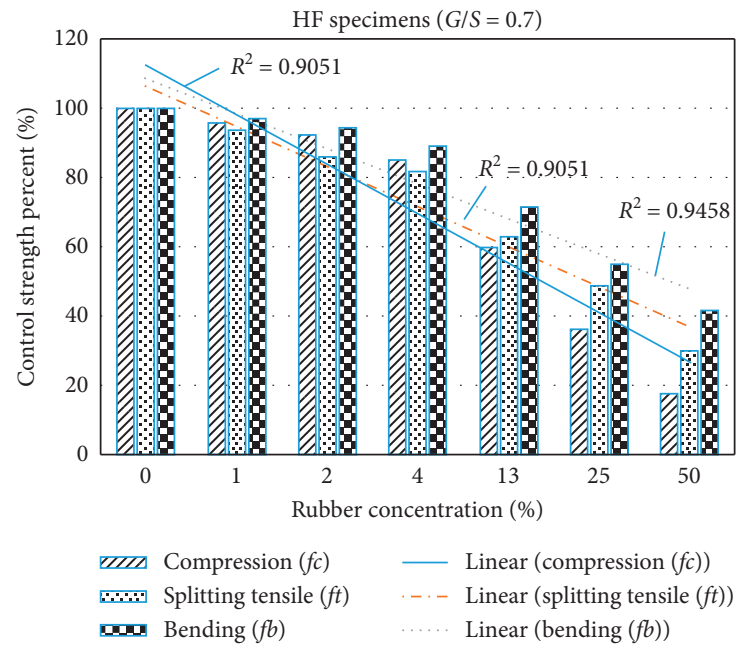

(b)

FIGURE 6: Variation of strengths with respect to control strength in different silicone rubber content. (a) LF specimens. (b) HF specimens.

silicone rubber content was not the same in compressive strength as it is in splitting tension strength. This is obvious in the bar chart of Figures 6(a) and 6(b), in which a trendline for the bars has been depicted, representing the three strengths of the bar chart. The results of this study were consistent with the results of a study conducted on rubberized concrete [24] that suggests that the rate of strengthloss in compression is higher than the rate of splitting tensile strength. Concrete strength, particularly in compression, depends on the paste quality, aggregate paste bond, and aggregate hardness. Generally substituting the harder dense natural aggregates with a softer, less dense silicone rubber will act as a stress concentrator, leading to microcracking of the concrete matrix, causing loss in strength [24]. This work concluded that the specimens with $G / S=0.7$ presented higher strength in compression, splitting tensile, and flexural strength in comparison with $G / S=1.1$, and failure mode has been changed from brittle to ductile failure with lower sound and separation of aggregate.
3.3. Proposed Model for Flexural Strength Reduction Factor of HSRC Specimens. To measure the flexural strength reduction of the HSRC specimens in connection with silicone rubber content in the mixture, an effort was made to simulate the flexural strength reduction by a characteristic function and the parameters of this function specified by regression analysis. The amount of silicon rubber content plays a vital role in the mechanical property of HRSC specimens demonstrated by test results. Hence, the properties of HSRC can be expressed by a function using the percentage of the amount of silicone rubber in the mixture. The $f b$-RF is defined by the ratio of the flexural strength of the mixture containing silicone rubber content $R$ to the strength of the control mixture. In the HSRC specimens, liquid silicone rubber has been replaced with the mineral aggregate of an equal volume. The content of liquid silicone rubber $R$ is a volume ratio, which indicates the percentage of volume of silicone rubber replaced with the same volume of mineral aggregates. At $0 \%$ rubber, $f b$-RF must be equal to 1 
TABLE 7: Parameter of reduction function for HSRC specimens at 28 days.

\begin{tabular}{lcc}
\hline \multirow{2}{*}{ Model parameter } & \multicolumn{2}{c}{ Concrete property } \\
& Flexural strength $(f b)$ in HF specimens & Flexural strength $(f b)$ in LF specimens \\
\hline$a$ & $0 / 12$ & $0 / 25$ \\
$b$ & $0 / 88$ & $0 / 75$ \\
$m$ & $4 / 1$ & $3 / 87$ \\
$R$-square & $0 / 94$ & $0 / 95$ \\
\hline
\end{tabular}

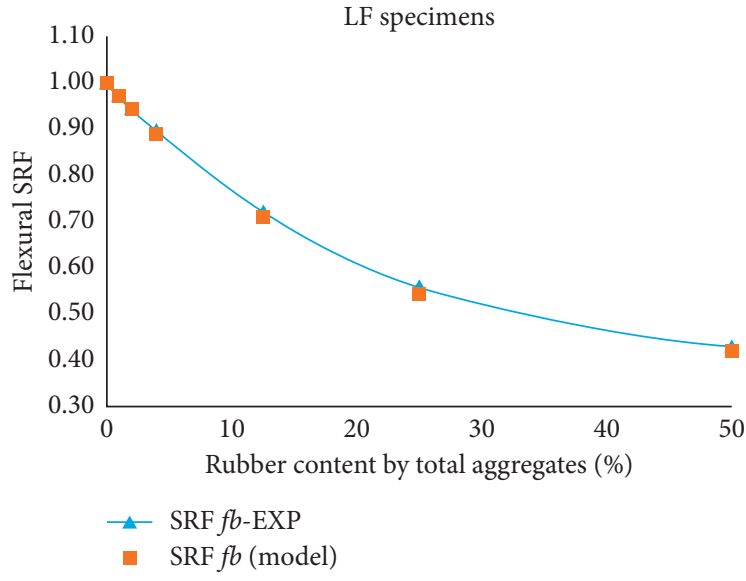

(a)

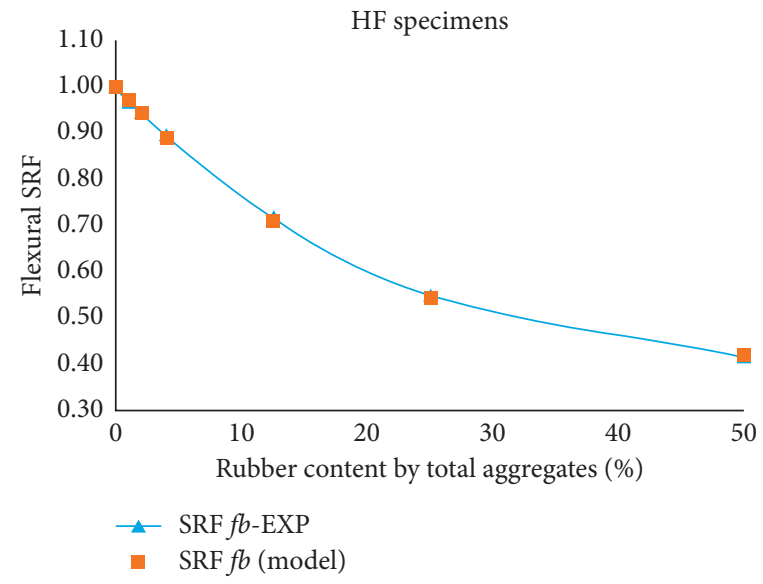

(b)

FIgURE 7: Comparison between experimental results and the proposed model. (a) LF specimens. (b) HF specimens.

(control mixture), and by increasing silicone rubber content in mixture, $f b$-RF will be decreased. According to similar studies carried out on rubber concrete by Khatib and Bayomy [24], the strength reduction function for flexural strength is used as follows:

$$
f b-\mathrm{RF}=a+b(1-R)^{m},
$$

where $f b$-RF is flexural reduction factor, and the following condition must be satisfied in the above equation:

$$
a+b=1
$$

where $a, b$, and $m$ are constant numeric parameters and $R$ is specified as silicone rubber content in a volumetric ratio of total mineral aggregate volume. $f b$-RF defined as flexural strength reduction factor. A numerical analysis was conducted on the data obtained by experimental tests to specify the parameters $(a, b, m)$. The error rate of the extracted functions was evaluated by the $R$-square test. The results are reported in Table 7 .

Figure 7 compares the results of experimental flexural tests and the proposed numerical model. Examination of the diagrams in Figure 7 shows that there is a very good correlation between the proposed model $f b$-RF and the test results for both HF and LF specimens, and the answers are almost consistent. According to the studies conducted by Khatib and Bayomy [24] on concrete containing tire rubber particles, the value of $m$ was considered to be 10 . In comparison with this study, it is found that the sensitivity of the results obtained from this study is less than the changes in comparison with research on tire rubber particles in concrete. Comparing the results of using liquid silicone rubber in concrete and crushed tire particles in concrete, it was concluded that the use of liquid silicone rubber instead of rubber particles caused mechanical properties such as compressive and flexural stresses to be reduced relatively less.

\section{Conclusions and Recommendations}

The results of this study showed that it is possible to use silicone rubber in the amounts of $1,2,4,12.5$, and $25 \%$ in executive works. The replacement of mineral aggregate with liquid silicone rubber in fresh concrete reduced compressive, splitting tensile, and flexural strength. Decrease in compressive strength was higher than the decrease in flexural strength and splitting tensile strength. The higher amount of silicone rubber results in the lower compressive and flexural and splitting tensile strength. Decrease in compressive strength was higher than the decrease in splitting tensile and flexural strength. The results show that, for a certain amount of silicone rubber and cement, HF specimens exhibited more flexural strength, about $7 \%$ than those of LF specimens. HSRC beam specimens exhibited more ductile behavior than plain concrete bending test. Failure was accompanied with lower sound than plain concrete. The failure of all the specimens was almost in one form. The main crack appeared in the middle of the span in the lower edge of the beam and continued upward. Physical exam of broken specimens indicated that there is a good engagement between silicone 
rubber particles and concrete constituent, so that these particles are not easily detachable from the concrete. In this study, liquid silicone rubber was added to ordinary concrete, then the resulting mixture was well stirred so that the liquid silicone rubber was evenly distributed in the mixture. Based on observations of broken specimens at the time of testing, the silicone rubber is randomly formed into different shapes, and according to the observations, some of them were in the form of filaments and due to their geometric shape, they were well involved in the concrete texture. Based on previous experiences of making rubber concrete with crushed particles of waste car tires, it was seen that in this case the rubber particles could be easily separated from the broken specimens, but in this study it was observed that the silicone rubber particles in concrete were well involved with the concrete texture and they were not easily detachable. Loaddeflection curves indicate that by the increasing silicone rubber content in concrete the deflection corresponding to cracking load was increased significantly, which is useful for structures located in severe environmental conditions. In elastic region before concrete cracking, the energy absorption capacity of HSRC is greater than control specimens. During the test, it was observed that, with the increase of silicone rubber in the specimens, they were broken with less noise and more flexibility was observed during the failure, which indicates that the use of silicone rubber in concrete improves the brittleness and inflexibility of the concrete.

\section{Data Availability}

All data will be available upon request.

\section{Disclosure}

This study is part of the second author's Ph.D. dissertation.

\section{Conflicts of Interest}

The authors declare that they have no conflicts of interest.

\section{Acknowledgments}

The authors are thankful for the support provided by the staff of Sharif University of Technology's Strong Floor Laboratory during this research. Partial financial support was provided by the Ministry of Energy (Golestan Regional Water Company), Iran National Science Foundation (INSF), and Center of Excellence in Structures and Earthquake Engineering.

\section{References}

[1] J. P. Romualdi and G. B. Batson, "Mechanics of crack arrest in concrete," Journal of the Engineering Mechanics Division, vol. 89, no. 3, pp. 147-168, 1963.

[2] İ. B. Topçu, "Assessment of the brittleness index of rubberized concretes," Cement and Concrete Research, vol. 27, no. 2, 1997.

[3] A. R. Khaloo, M. Dehestani, and P. Rahmatabadi, "Mechanical properties of concrete containing a high volume of tire-rubber particles," Waste Management, vol. 28, no. 12, pp. 2472-2482, 2008.
[4] R. K. Hamdan and S. I. Sarsam, "Impact of rejuvenators type on physical properties of aged asphalt cement," Civil Engineering Journal, vol. 5, no. 9, pp. 2058-2069, 2019.

[5] G. H. Xu, "Dynamic parameter optimization and experimental study of tuned slab damper on metro systems," Shock and Vibration, vol. 2019, 2019.

[6] E. Ganjian and M. Khorami, "Scrap-tyre-rubber replacement for aggregate and filler in concrete," Construction and Building Materials, vol. 23, no. 5, pp. 1828-1836, 2009.

[7] A. A. Kadhim and H. M. K. Al-Mutairee, "An experimental study on behavior of sustainable rubberized concrete mixes," Civil Engineering Journal, vol. 6, no. 7, pp. 1273-1285, 2020.

[8] H. L. Li, Y. Xu, P. Y. Chen, J. J. Ge, and F. Wu, "Impact energy consumption of high-volume rubber concrete with silica fume," Advances in Civil Engineering, vol. 2019, 2019.

[9] V. R. Riley and I. Razl, "Polymer additives for cement composites: a review," Composites, vol. 5, no. 1, 1974.

[10] K. Malek, "Promoting the use of crumb rubber concrete in developing countries," Waste Management, vol. 28, no. 11, pp. 2171-2176, 2008.

[11] B. Fazelabdolabadi and M. H. Golestan, "Towards bayesian quantification of permeability in micro-scale porous structures-the database of micro networks," HighTech and Innovation Journal, vol. 1, no. 4, pp. 148-160, 2020.

[12] E. Güneyisi, M. Gesoğlu, and T. Özturan, "Properties of rubberized concretes containing silica fume," Cement and Concrete Research, vol. 34, no. 12, 2004.

[13] E. A. Cherney and R. S. Gorur, "RTV silicone rubber coatings for outdoor insulators," IEEE Transactions on Dielectrics and Electrical Insulation, vol. 6, no. 5, pp. 605-611, 1999.

[14] A. J. Shaukat, H. Feng, A. Khitab, and A. Jan, "Effect of admixtures on mechanical properties of cementitious mortar," Civil Engineering Journal, vol. 6, no. 11, pp. 2175-2187, 2020.

[15] E. Keith, "Polmanteer, silicone rubber, its development and technological progress," Rubber Chemistry and Technology, vol. 61, no. 3, pp. 470-502, 1988.

[16] L. Furgani, M. A. Hariri-Ardebili, M. Meghella, and S. M. Seyed-Kolbadi, "On the dynamic capacity of concrete dams," Infrastructures, vol. 4, no. 3, p. 57, 2019.

[17] S. M. S. Kolbadi, H. Davoodian, and S. M. S. Kolbadi, "Evaluation of nonlinear behavior of reinforced concrete frames by explosive dynamic loading using finite element method," Civil Engineering Journal, vol. 3, no. 12, p. 1198, 2018.

[18] S. C. Shit and P. Shah, "A review on silicone rubber," Civil Engineering Journal, vol. 36, pp. 355-365, 2013.

[19] ASTM C 192/06 Standard Practice for Making and Curing Concrete Test Specimens in the Laboratory.

[20] ASTM C 143 Standard Method of Test for Slump of Hydraulic Cement Concrete.

[21] ASTM C138/C138M-17a Standard Test Method for Density (Unit Weight), Yield, and Air Content (Gravimetric) of Concrete.

[22] ASTM C78, 2018, Standard Test Method for Flexural Strength of Concrete (Using Simple Beam with Third-Point Loading).

[23] C. G. Papakonstantinou and M. J. Tobolski, "Use of waste tire steel beads in Portland cement concrete," Cement Concrete Research, vol. 36, p. 1691, 2006.

[24] Z. K. Khatib and F. M. Bayomy, "Rubberized Portland cement concrete," Cement Concrete Research, vol. 11, no. 3, pp. 206-213, 1999. 